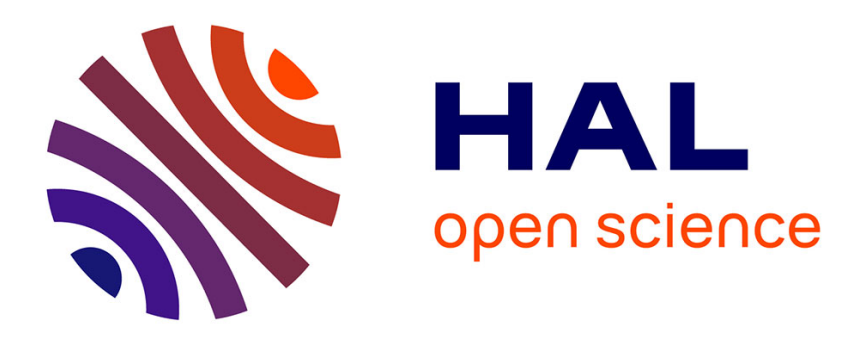

\title{
Subjectivism without Idealization and Adaptive Preferences
}

\author{
Stéphane Lemaire
}

\section{To cite this version:}

Stéphane Lemaire. Subjectivism without Idealization and Adaptive Preferences. Utilitas, 2020, pp.116. 10.1017/S095382082000031X . hal-03016647

\section{HAL Id: hal-03016647 https://hal-univ-rennes1.archives-ouvertes.fr/hal-03016647}

Submitted on 20 Nov 2020

HAL is a multi-disciplinary open access archive for the deposit and dissemination of scientific research documents, whether they are published or not. The documents may come from teaching and research institutions in France or abroad, or from public or private research centers.
L'archive ouverte pluridisciplinaire HAL, est destinée au dépôt et à la diffusion de documents scientifiques de niveau recherche, publiés ou non, émanant des établissements d'enseignement et de recherche français ou étrangers, des laboratoires publics ou privés. 


\title{
Subjectivism without idealization and adaptive preferences \\ Stéphane Lemaire \\ Université de Rennes 1 \\ stephane.lemaire@univ-rennes1.fr
}

\begin{abstract}
Subjectivism about well-being holds that an object contributes to one's well-being to the extent that one has a pro-attitude toward this object under certain conditions. Most subjectivists have contended that these conditions should be ideal. One reason in favor of this idea is that when people adapt their pro-attitudes to situations of oppression, the levels of well-being they may attain is diminished. Nevertheless, I first argue that appealing to idealized conditions of autonomy or any other condition to erase or replace adaptive pro-attitudes is mistaken. Second, I show that the most natural version of subjectivism that does not appeal to any such idealizing condition can explain why the well-being of people having adaptive pro-attitudes should not be restricted to the fulfillment of these pro-attitudes. In sum, the existence of adaptive preferences does not militate in favor of the introduction of conditions of idealization but against it.
\end{abstract}




\section{Introduction}

Subjectivism about well-being is the claim that an object, event or state of affairs contributes to an individual's well-being to the extent that it constitutes the content of one of his or her pro-attitudes under certain conditions. Debates among subjectivists concerning the best way to flesh out this schema more precisely are numerous. One especially important question bears on the conditions under which the pro-attitude's object is good for the bearer of the pro-attitude. It is fair to say that subjectivists have long thought that the relevant conditions imply a certain amount of idealization (Sidgwick 1907, Brandt 1997).

A central argument in favor of idealized conditions is that we often have mistaken beliefs or insufficient information about the objects of our pro-attitudes. As a result, it is no surprise that obtaining them often brings more disappointment than any contribution to our well-being. The suggestion has thus been that an object contributes to an individual's well-being if and only if this individual would have the relevant proattitude under a condition of complete information or full experience of the object (Sobel 2009, Dorsey 2017). However, it has been recently argued that subjectivism may circumvent this problem and others raised by "defective" pro-attitudes without introducing idealized conditions of information (Heathwood 2005, Lin 2018, Lemaire 2016). In other words, it may be that an actualist subjectivism (or actualism for short) that does not appeal to idealized conditions, has more resources than it has been thought.

In the present paper, I do not try to justify or reject the necessity for subjectivism to appeal to idealized conditions of information and my discussion will be neutral with regard to this debate. Rather, I aim to contribute to the emerging actualist trend within subjectivism by focusing on the challenge that adaptive preferences-and more generally adaptive pro-attitudes - raise for this trend. Indeed, since Elster (1983), Sen (1984) and Nussbaum (2001), the existence of adaptive preferences has been presented as raising an important objection to actualism understood in terms of subjective preferences. Suppose some people have adapted their preferences in order to cope with a situation of oppression. It seems then that claiming that their well-being consists in part in the satisfaction of their actual adapted preferences is just to " give sanctity to that distortion » (Sen 1984: 309), that is, to legitimize the oppression to which they have adapted, and finally to reduce the well-being they could otherwise attain. To overcome this problem, a natural response for subjectivism has been to introduce a condition of autonomy on preferences that erases or replaces them when they are adaptive. For instance, one may contend that the preferences that are relevant for well-being are those one would have if the preferences were autonomous. However, the present paper argues that this line of response has unacceptable consequences that only actualism avoids. Moreover, I show that it is an error to think that actualism would "give sanctity" to the result of oppression. Notice however that the aim of the paper is not to offer a full response to the numerous moral and political problems raised by adaptive preferences and the oppression that breeds them. At best, the paper does some groundwork to understand the well-being of people with adaptive preferences that may be relevant to answer some moral and political problems they raise if one is attracted by a subjectivist approach to well-being.

Now, in order to show that subjectivist theories about well-being confronted with the existence of adaptive preferences should be actualist, the paper unfolds as follows. To begin with, Section Two characterizes the adaptive preferences that seem 
problematic for a subjectivist approach to well-being. The various idealizing strategies that subjectivism has introduced or could introduce to handle the problem are then presented. Section Three opposes all these strategies on the ground that they are wrong to exclude the objects, or some of the objects, of adaptive preferences as contributing to well-being. Section Four then turns to the positive. If one must not exclude or replace adaptive preferences, can a version of actualism overcome the problem that Sen and Nussbaum have raised? I argue that a natural version of actualism that I call TemporallyNeutral Actualism ${ }^{1}$ meets the challenge. I finally show that this version of actualism should also be preferred to more sophisticated versions of subjectivism that would try to combine features of actualism and idealizing versions of subjectivism. Section Five closes the paper.

\section{Subjectivism and adaptive preferences}

\subsection{Varieties of subjectivism}

Before considering the problem that adaptive preferences raise for subjectivism, a few clarifications about subjectivism and the aim of this paper are in order. As stated above, subjectivism contends that an object contributes to an individual's well-being if and only if this individual has a certain pro-attitude toward this object under certain conditions. Of course, several elements of this schematic formula need to be specified. Concerning the relevant pro-attitude, desiring is the most popular candidate. According to the desire-theory of well-being, an object contributes to an individual's well-being if and only if she desires this object under certain conditions. However, the desire-theory is only one of many potential options. For instance, one may claim instead that an object contributes to one's well-being to the extent that one values the object (Tiberius 2018) or that one believes that the object is good for oneself (Dorsey 2012). An alternative suggestion is that the relevant subjective pro-attitude is one of preferring an object to another (Baber 2007). In this latter case, the subjectivist approach will not explicate the notion of well-being or what is good for an individual but of what is better for someone. In any case, the present paper does not try to adjudicate these debates, although for simplicity's sake I will often present my discussion under the assumption that desire is the relevant pro-attitude. Moreover, I believe that subjectivists who disagree on that point will be able to transpose mutatis mutandis the argument that follows using their preferred pro-attitude.

I will also remain neutral on several other elements that a complete subjectivist account should specify. In particular, I will not decide whether the subject's well-being is increased when the object of the pro-attitude is instantiated or when the pro-attitude is held. ${ }^{2}$ Neither will I take a stance on whether what matters is the real fulfillment of desires or the belief that they are fulfilled. ${ }^{3}$ Nor will I consider whether the good is the object of the pro-attitude, or the more complex state of fulfillment of the pro-attitude. ${ }^{4}$

\footnotetext{
1 I borrow this term from Parfit who considers the view in his discussion of the desiretheory of reason. See Parfit (2011: 105).

${ }^{2}$ See Dorsey (2013a) for a defense of the latter view.

${ }^{3}$ See for instance Heathwood (2006) for discussion.

4 See Rabinowicz \& Österberg's (1996) seminal paper.
} 
In short, the aim of my discussion is solely to assess whether the existence of adaptive pro-attitudes should lead subjectivists to introduce a condition of idealization or, on the contrary, to devise an appropriate actualism.

\subsection{What is the problem of adaptive preferences?}

Let us now turn to the problem raised by adaptive preferences or desires. To begin with, it would be useful to have a workable definition of adaptive desires. The general idea seems to be that a desire is adaptive if it is the result of a transformation or formation process that is prudentially beneficial by diminishing or avoiding frustration in one's circumstances. Yet, it is worth noticing that this definition allows for adaptive preferences that raise no problem for subjectivism. Bruckner (2009: 314) presents the case of Ursula, a woman who lost her husband. Before his death, she desired to spend her life with him. But presently this option is no longer feasible and, during the mourning process, she ends up losing her desire. This is surely an adaptation and it is moreover prudentially beneficial given her situation. Nevertheless, such adaptations don't raise any problem for actualism: to admit that her well-being after adaptation is no longer constituted by the desire which she has renounced does not seem either wrong or problematic. Although her situation is sad, it seems that we lack any ground to criticize her prudential adaptation.

In contrast, adaptive preferences that are prudential responses to oppression are obviously worrisome. Nussbaum describes the case of Jayamma, an Indian women who works at a brick kiln and who carries brick on her head all the day long without any hope of obtaining an easier, more valued or better paid task. Moreover, although men start by also doing the same heavy labor, they rapidly graduate to the more skilled and less physically demanding task of brick molding and kiln loading which are paid up to twice as much. Despite all this, Jayamma « seems to accept this as the way things are » (Nussbaum 2001: 23) and doesn't « think the division of labor at the brick kiln bad. » (2001: 140). According to Nussbaum, all this reveals that Jayamma has adapted her desires to her condition since this allows her to be satisfied with what she has and to avoid experiencing frustration.

If this is a real case of adaptive desires, a point to which I come back in the next paragraph, it seems to be a problematic one for an actualist version of subjectivism. Indeed, the result of her prudential adaptation is to diminish in virtue of unjust social circumstances the well-being that Jayamma can attain. The point is made salient if we were to consider a policy aiming at the welfare of Jayamma. If such a policy were to take Jayamma's welfare as consisting in the fulfillment of her adaptive desires, then it would unacceptably legitimize a distribution of labor that is obviously unjust.

Baber (2007) has however argued that there is little reason to believe that such examples really involve an adaptation of desires. For sure, Jayamma accepts working at the brick kiln for only five rupees a day, yet it seems that this is merely because it is the best salary she can get. Why claim that she does not desire a higher salary? The fact that she does not hope to improve her salary merely reflects her beliefs about which desires

can be satisfied. Jayamma surely adapts her choice to her beliefs about what is attainable, but there isn't any reason to suggest that she has also adapted her desires. Indeed, if a better employment with a better salary were offered to her, she would certainly not refuse it. She would not need to acquire or reacquire a desire for a better job. Thus, the possibility of an immediate reversal of her 'adaptive desires' seems to show that her desires have never changed. Hence, Baber claims that if adaptive preferences are 
'unstable' in the terms of Elster (1983: 113), it should be clear that they are not adaptive: " if the fox is disposed to jump at the grapes as soon as they become available, then we should say that he has wanted them all along ». (Baber 2007: 112).

Now, does this show that the existence of problematic adaptive preferences is a myth and that they raise no problem for actualism? This would be too hasty because numerous adaptive preferences are not immediately reversible and often result from the internalization of oppressive cultural norms such as gender norms. For instance, people tend to see as most desirable the jobs that are considered suited to them within their culture. And once the preferences are built through these normative expectations, they are not easily reversed. ${ }^{5}$ For a job previously unavailable and taken as inappropriate for women to become desirable, it is not sufficient that it becomes merely available. Notice, by the way, that this is why the real problem posed by adaptive preferences is not at its core a problem raised by a lack of information, or by momentary circumstances.

If all this is correct, then it appears that desires that are not immediately reversible and that are prudentially adapted to morally illegitimate circumstances are those that pose a real challenge to actualism. For sure, such an adaptation to oppression is prudential and leads to higher level of satisfaction given the oppression. But the problem is that the fulfillment of adaptive desires will often lead to a lower level of wellbeing than the fulfillment of the original non-adaptive ones would have. After all, gender norms aim to secure that some attractive activities and positions are refused to women. Thus, the worry is that actualism may perpetuate the diminishment of well-being that result from people's adaptive preferences and therefore legitimize the initial injustice done to them.

I will therefore take it that adaptive preferences raise a real problem for subjectivism insofar as they are non-immediately reversible desires that have been formed as adaptation to morally criticizable circumstances. ${ }^{6}$

\subsection{Introducing an idealization condition to salvage subjectivism}

Now that we have a better grasp on the adaptive preferences that raise a problem for subjectivism, let us see how subjectivism could overcome it. Since the problem targets the actual adaptive preferences of individuals, a natural solution is, at first sight, to introduce an idealization condition on preferences that will dispose of them. Such a condition may be either a restriction on actual preferences or a counterfactual condition that erases and replaces adaptive preferences. In the former case, I will talk of restricted actualism and in the latter of counterfactual subjectivism (or counterfactualism for short).

Whichever path we take, it remains to be settled which idealizing condition should be introduced. Insofar as adaptive preferences are adaptations to contexts of oppression, the introduction of an externalist condition of autonomy understood in causal or historical terms is surely an attractive option. If we introduce this condition as a restriction on the preferences that contribute to people's well-being, we have the following version of restricted actualism: a desired object contributes to a person's wellbeing if and only if this desire has been formed or could have been formed in a context

\footnotetext{
${ }^{5}$ For a development of this objection to Baber, see Stoljar (2014: 247).

${ }^{6}$ For similar characterizations of problematic adaptive preferences, see Superson (2005: 109) and Enoch (2020: 185).
} 
free of oppression, manipulation, unfairness, etc. A close but slightly different view would result if one uses Christman's theory of autonomy that offers an internalized version of such a historical condition. In his view, desires are autonomous to the extent that one would endorse their causal history from an unbiased, well-informed and rational standpoint (1991: 11). We may then claim that a desired object contributes to well-being only if one would endorse the desire's causal history from an unbiased, wellinformed and rational standpoint. In any case, whether we introduce a causal condition of autonomy or Christman's condition, they will both erase all adaptive preferences.

Alternatively, one may introduce an internalist condition of autonomy within a restricted actualism that will exclude only some adaptive preferences. Internalist versions of autonomy are numerous but they may all be understood as involving a form of endorsement or coherence. For instance, according to Dworkin's (1988) theory of autonomy, preferences are autonomous to the extent that they are or would be endorsed by their holders. Relying on this theory, Bruckner then claims that only preferences that are endorsed or would be endorsed under examination (2009: 322) contribute to their bearer's well-being. If one further adopts a hierarchical understanding of endorsement (Frankfurt 2018), one could then claim that desired objects contribute to people's well-being only if the latter desires are or would be after reflection the object of second order desires. Alternatively, one may prefer a stronger conception of endorsement according to which « [a] utonomy consists in deciding for oneself what is valuable and living one's life in accordance with that decision. " (Colburn 2011: 61). ${ }^{7}$ Building on such an account of autonomy, one would claim that only preferences one has decided to have or would have decided to have would make one better off. Finally, another avenue for internalist views about autonomy is to claim that autonomous preferences are those that are coherent. ${ }^{8}$ For instance, one may suggest that preferences contribute to well-being to the extent that one would keep them under a condition of minimal revision for coherence (Dorsey 2013b). In any case, what is important with these internalist conditions of autonomy is that a restricted actualism that relies on one of them will not exclude all adaptive preferences since the latter may be endorsed or be part of a coherent set of preferences.

In sum, it seems as if an idealizing subjectivism has numerous options to overcome the problem of adaptive preferences. It can either introduce a restriction on preferences that excludes adaptive preferences or propose a counterfactual subjectivism that excludes them and replaces them. And it can do so for all adaptive preferences through an external/causal externalist condition of autonomy or only for a certain subset of them by relying on an internalist condition of autonomy or a mere condition of coherence. ${ }^{9}$ The next section shows however that all these subjectivist conceptions of well-being that aim at excluding (some) adaptive preferences are defective in virtue of this very exclusion.

\section{Non-reversible adaptive preferences and well-being}

\footnotetext{
${ }^{7}$ But see also Elster (1983) and Raz (1986) for similar views.

${ }^{8}$ It is worth noting that a coherence condition may not be primarily seen as a condition of autonomy. According to Dorsey, the condition is required to avoid indeterminacy when people seem to hold contradictory desires.

${ }^{9}$ I will not consider substantial conditions of autonomy since they are by nature inconsistent with a subjectivist approach to well-being.
} 
In order to explain why subjectivism should neither exclude nor replace adaptive preferences, I will proceed by steps. I start with a case aiming to show that a restricted actualism that relies on an externalist condition of autonomy excludes too much. Then, I extend this argument in several ways. A first extension argues that even if we move to an internalist condition of autonomy or a condition of coherence, a slight variation on the original case raises the same objection. A second extension shows that the very same objection applies also to counterfactualism whether it relies on an externalist or internalist conception of autonomy. If these arguments are correct, they will have shown that any restricted or counterfactual subjectivism that erases or replaces adaptive preferences must be rejected.

\subsection{Against restricted actualism with an externalist autonomy clause}

I first argue against a restricted actualism that relies on an externalist condition of autonomy by borrowing a case proposed by Khader (2013). Consider Lucy, who is an elderly woman with a terminal disease. Being a full-time caregiver as her mother was, she believes that the role of women is to take care of others, especially of her husband and her children. She spent her life in accordance with this view, to which she fully adheres. In other words, she desired this life and did not desire anything else for herself. Moreover, she led a life that she sees as a happy one. Now, she is at the end of her life and afflicted with a terminal disease. Because she can no longer look after others, what she wants most is to get palliative care and die. Importantly, this is not because she suffers from her disease or is depressed. Rather, she feels that there is no sense in staying alive as a burden if she can no longer take care of others. In fact, she correctly anticipates that she would feel bad staying at home while being useless.

Obviously, her adherence to her lifestyle and more specifically her ensuing desire to get palliative care are adaptations of the worst sort since they are caused by social injustice. Therefore, her desire would be excluded by all versions of the historical clause: she did not control the conditions under which her desire was formed; the desire is the outcome of an unfair situation with regard to positions available to women. Even the weakest version of the historical clause proposed by Christman would exclude her desire: an unbiased Lucy would not endorse her desire if she was fully informed and aware that it resulted from oppression.

However, Khader claims that Lucy's actual strongest desire, which is to get palliative care and die, should be respected insofar as this is what will most contribute to her well-being in her present situation. I share this claim and I believe that there are several good reasons to accept it. The first is that she has a strong desire that is perfectly coherent with her life choices. Hence, to deny that fulfilling her desire will contribute to her well-being boils down to claiming that her extreme frustration, the impression that her will is not respected will not downgrade her well-being. This seems hardly defensible. Of course, if there was enough time for her to become more autonomous, then one might think that discarding her present desire could lead to more well-being in the future. But this is precisely not her situation. Her frustration and the guilt she will experience in being, as she thinks, a burden for others, will not be compensated in any way. In addition, we know that becoming more autonomous often takes time and involves going through numerous hardships. Gaining more autonomy is not, at least not in Lucy's case as it is presented, merely giving up, all of sudden, the desires and values around which her life has been constructed. Moreover, to claim that her most important desire should simply count for nothing in her well-being seems like an additional 
violation of her autonomy in the name of autonomy. Finally, it would even be cruel to destabilize her at the very moment at which she has to face her coming death, a moment at which we are certainly authorized to keep our innocent certitudes and desires, however mistaken they may be. I conclude that any restricted version of subjectivism that introduces a historical clause or any other clause the effect of which is to erase Lucy's adaptive desire is unacceptable. ${ }^{10}$

\subsection{Against restricted actualism with an internalist autonomy clause}

In Lucy's case, a central consideration has been that her desire to have palliative care and die is endorsed or coheres with her other desires. This may lead one to suggest that a restricted actualism that relies on a condition of endorsement or coherence offers a better prospect. As we have already seen, such weaker forms of restricted actualism have been defended. Bruckner (2009) claims that as long as desires satisfy a condition of possible endorsement, their objects contribute to well-being. Similarly, Dorsey (2013b: 45-46; 2017: 206) argues that if adaptive preferences are deeply integrated and therefore cohere with one's other preferences, then there is no reason to reject them. Khader herself draws a similar conclusion from Lucy's case: the desires that should be taken into consideration, at least for decisions at the end of life, are those that would satisfy a condition of coherence.

Unfortunately, such a restricted actualism remains too strong a remedy for the problem of adaptive preferences. To see this, it suffices to slightly modify Lucy's case by introducing preferences that are not endorsed or lack coherence with her other desires. Suppose that Martha is perfectly similar to Lucy, except that she experiences from time to time dissatisfaction with her life. She sometimes dreams of another life, though her desire never led her to make real changes in her life. Or maybe she thinks that she would like to leave everything though she does not endorse this desire. ${ }^{11}$ However, like Lucy, Martha desires now to get palliative care and die.

Does the object of this desire contribute to Martha's well-being on a version of restricted actualism with an internalist autonomy or coherence condition? It seems that whatever the precise condition of that type we might consider, Martha's case can be designed to give a negative answer. For instance, one can stipulate that she didn't decide to desire to have palliative care and die; it only appeared to her as the best option. Or, she may not endorse her desire; she may have some weak second order desire to change her first order adaptive desires. Finally, her other first order desires may not be fully coherent with her desire to have palliative care and die. Hence, under this description, restricted actualism with a coherence condition will conclude that the object of Martha's incoherent or non-endorsed adaptive desire to have palliative care and die doesn't contribute to her well-being.

Yet, this response is unacceptable for the very same reasons that we have identified in Lucy's case. For sure, the tension in her preferences may leave room to help her to become more autonomous under some development of the case. But the crucial

10 The point applies in particular to Superson (2005: 123) who defends a substantial view of autonomy. For she claims that because adaptive preferences are incompatible with one's sense of one's equal moral worth, they must all be excluded.

11 In fact, the case of Martha may be more faithful to the mindset of women undergoing cultural oppression. See in particular Uma Narayan's (2002) description of women from the conservative Sufi Pirzada community of Old Dehli. 
point is that it is not true for any development. Even if Martha's desires are incoherent or lack endorsement, it does not follow that her adaptive preferences contribute nothing in her well-being. Her actual more autonomous desires or her refusal to endorse her adaptive preferences may be too feeble for her to build her life on their fulfillment in the remaining time she has left. After all, her adaptive desires have been central to her whole life and the mere fact that Martha has an internal conflict may not diminish sufficiently the cost that being a burden for her family will imply for her given her present actual adaptive preference.

At this juncture, the defenders of a weak coherence condition of autonomy may reply that their view does not exclude Martha's desire (Dorsey 2013b). According to them, the fact that Martha's desire is in tension with some others is not sufficient to exclude it. For a desire to be excluded, it must be in tension with desires that are more numerous, weigh more or form a stronger web. If, on the contrary, as in Martha's case, the desire belongs to a set of desires we can counterfactually build by making her actual set of desires more coherent, then the desire contributes to Martha's well-being.

But this even weaker version of the coherence condition must also be rejected insofar as it still erases adaptive desires that contribute to well-being. Even if an adaptive desire is in tension with a weightier set of desires, it does not follow that it contributes nothing to well-being. First, to make such a claim, one would have to contend that the frustration of this adaptive desire will not diminish its holder's wellbeing. But nothing allows such a conclusion: if she decides to act in accordance with her most coherent set of desires and thereby frustrates her adaptive desire that is in tension with the latter, this will diminish her well-being. So, an assessment of her well-being cannot assume that the existence of her adaptive desire has no impact on her wellbeing. ${ }^{12}$ Second, if this person was transposed into a context in which her more coherent set of desires would be impossible to fulfill for various contingent reasons, then satisfying her adaptive desires may become what would contribute most to her wellbeing. But for a desire to contribute most to one's well-being in a certain context, its object must contribute to it in general. Therefore, since restricted subjectivism with an internalist clause excludes incoherent adaptive preferences, it cannot offer the proper account of her well-being in this circumstance.

I therefore conclude that even a restricted actualism that introduces something like an internalist autonomy or a coherence condition to exclude only some adaptive preferences should be rejected precisely because this exclusion remains a mistake. ${ }^{13}$

\subsection{Extending the argument against counterfactualism}

The two previous sub-sections have shown that restricted actualism is mistaken. The exclusion of all or some adaptive preferences cannot be the right solution for subjectivism to overcome the problem raised by these preferences. If this is correct, then the argument immediately extends to a counterfactualism that appeals to an idealizing condition of autonomy or coherence. Recall that counterfactualism is the view that an object contributes to an individual's well-being insofar as he or she would desire the object under some idealized condition. Hence, if counterfactualism relies on an idealized

12 Terlazzo (2017a: 420-421) makes a similar point.

${ }^{13}$ I take it that Khader herself stops halfway. Indeed, after having argued that a condition of autonomy in historical or substantial terms is mistaken, she claims that, at least in end of life contexts, adaptive desires must be coherent to be taken into account. 
condition of autonomy understood either in externalist or internalist terms, then it will exclude respectively all or some adaptive preferences as contributing to well-being, and replace them with autonomous or at least coherent preferences. Since we have seen that this complete or partial exclusion of adapted preferences is unacceptable, counterfactualism falls prey to the same defects that have been pointed out in restricted actualism.

In fact, counterfactualism is even worse since it not only erases adaptive desires but also replaces them with counterfactual ones. Indeed, an immediate consequence of counterfactualism is that people's well-being can rely on desires that they actually lack. In other words, counterfactualism would then propose that some objects can contribute to people's well-being even if the latter are not motivated by these objects, a view of well-being that seems alienating (Railton 2003). Since subjectivists have traditionally reproached ${ }^{14}$ objectivists for making this error, they surely should themselves avoid it.

In sum, it is not only restricted actualism but also counterfactualism that is unable to handle properly the problem of adaptive preferences. Moreover, insofar as their fault is to erase or replace adaptive preferences, any version of subjectivism that would erase or replace them must also be rejected. In other words, we have a good reason to adopt actualism without introducing any restriction on it.

\subsection{Two further arguments for actualism}

Beyond the arguments just presented, two general considerations also militate in favor of the contribution of adaptive preferences to well-being.

First, I believe that a general principle of practical reason vindicates that, even if it would be better to free oneself from some desires from a prudential perspective, they still contribute to one's well-being. Take for instance the desire to smoke. Even if it is rational to quit smoking now for its benefits in the long run, it might not be the best thing to do now if one is overloaded with work to finish or if one is confronting hardships, as long as there will be a more appropriate moment in the future and to the extent that the costs of delaying will be balanced by its benefits. ${ }^{15}$ In other words, the following general principle of practical reason seems correct: even if a certain action constitutes a rational choice at a given moment, it may not be the best plan to follow if the cost could be reduced or more manageable in the future. ${ }^{16}$ And from this general truth, it seems that a case can be made for adaptive preferences: even if it could be better to get rid of actual adaptive preferences for our benefit in the long run, the best plan could combine both their satisfaction in a short-term perspective and their elimination in a long-term perspective. Even if non-adaptive preferences will provide a higher level of well-being in the future, the best road for this self-transformation may

${ }^{14}$ I introduce the adverb «traditionally » since more recently objectivists have tried to avoid this reproach by claiming that the objective goods that constitute well-being are themselves partly constituted by, or dependent on, affective states (Fletcher 2013).

${ }^{15}$ As Bratman (1987) has shown, this is not mere procrastination but on the contrary, to have a rational perspective on choice that takes plans as their objects and not individual choices in isolation.

${ }^{16}$ For a complete defense of this point, see Bratman (1987). A crucial point here is that the cost of quitting smoking must not be stable. I believe this is correct. To get rid of an addiction is surely easier if your life is otherwise going well. 
encompass the fulfillment from time to time of adaptive preferences as long as one possesses them.

Second, we should note that adaptive preferences are rooted in desires that are important and are plausibly universal. For instance, fulfilling roles favored by culture is an important source of satisfaction because we thereby also fulfill desires to be respected, loved, well-integrated, valued for what we are doing, etc. Hence, even if these roles put undue limits on one's long term well-being, it does not follow that adaptive desires are merely superficial features of those who have them. The mere fact that it would be better not to have them does not mean that they could be erased as playing no role in well-being. On the contrary, they are often part of one's deep self and even when that is not the case, they cannot be counted for nothing.

The general conclusion is clear. Subjectivism about well-being should always take into account the objects of actual adaptive desires as contributing to well-being. This is not to say that the reasons to fulfill these desires will always outweigh the reasons to frustrate them. Surely not. This is only true in a minority of cases and especially in end of life contexts or situations in which people are under severe pressure. But for the objects of adaptive preferences to outweigh considerations aiming at the increase of autonomy in a minority of circumstances, one must never discard them from the outset. We first need to take the objects of people's actual adaptive preferences as contributing to their well-being in order to decide from there, depending on the particular context, which objects contribute most to their well-being.

\section{Temporally-neutral actualism}

\subsection{Actualism at a time and over lifetime}

If the argument so far is correct, actualism is right to count the satisfaction and frustration of one's present actual adaptive preferences as always contributing (respectively positively and negatively) to one's well-being. However, this is insufficient to claim that a subjectivist approach to well-being should remain actualist in response to the problems that adaptive preferences raise. After all, devising a welfare policy by relying on adaptive preferences without assessing them seems wrong because it seems that it unduly limits the level of well-being their bearers could attain. Moreover, we have noticed that if Lucy or Martha were not at the end of their life, it would be unacceptable to reduce their well-being to the fulfillment of their present actual desires, and among them their present actual adaptive desires. In Sen's words, this would "give sanctity" to the result of a process that is already unjust. We must therefore ask ourselves whether actualism is able to provide a satisfying treatment of this problem.

I believe that the most natural development of actualism can offer one. However, we must first develop actualism as a theory of well-being over a lifetime. To make a start, subjectivism must obviously contend that, beyond one's present preferences, one's future preferences are also relevant to one's well-being over a lifetime. In other words, a subjectivist theory of well-being over a lifetime must claim that well-being over a lifetime is constructed from the fulfillment and frustration of all the desires that one actually had, has and will have in one's life. In its simplest version, well-being over a lifetime is the aggregation of all the actual desires that one had, has or will have that 
were satisfied minus all those that remained unfulfilled. ${ }^{17}$ Alternatively, one may defend more sophisticated rules of integration. In any case, there is no need to address this debate to show that an actualist subjectivism can overcome the problem of adaptive preferences. Therefore, I will stick here to the following general characterization of actualism over a lifetime:

\section{Temporally-Neutral-Actualism (TNA for short)}

An individual's well-being over her lifetime is constructed from the fulfillment and frustration of all the desires that she actually had, has or will have. ${ }^{18}$

A major reason to favor this general characterization is that it fits the temporal scheme that underlies nearly all conceptions of well-being over a lifetime. For instance, hedonism in its simplest form is generally understood as claiming that an individual's well-being is obtained by summing up her past, present and future pleasures and displeasures.

Now, an important consequence of TNA is that one may have prudential reasons to act in order to change one's desires whenever the fulfillment of the acquired desires would provide more well-being than our present ones and if these gains are not outweighed by the costs of this change. For instance, consider Arthur whose desire to play the piano as an amateur remains frustrating given, let us suppose, his lack of musical talent. Suppose now that once playing ping pong, he discovers that he has much more fun there. As a result, his desire to play piano is extinguished and is replaced by a desire to play ping pong. This is obviously a case in which someone is prudentially justified in changing his or her desires insofar as the change provides more well-being.

In sum, TNA implies that the consideration of one's good from a prudential perspective does not rely only on one's actual present desires but also on the potential desires one may actually acquire in the future and how they would contribute to one's well-being. As we will now see, this consequence of TNA provides a response to Sen and Nussbaum's objection.

\subsection{How Temporally-Neutral-Actualism deals with adaptive preferences}

Let us recall the objection. The worry is that the problematic cases of adaptive preferences, such as those that result from gender oppression, tend to diminish the well-

\footnotetext{
17 One might also plausibly claim that an additional concurrence condition must be required: for the fulfilment or frustration of one's desires to contribute to one's wellbeing, one must hold them while they are fulfilled or frustrated. See Heathwood (2006) for this condition.

18 Notice that TNA has already been identified and even endorsed by certain actualists. Murphy emphasizes in a note (1999: 270, endnote 5) that « actual » does not mean " present » and therefore that his defense of actualism about information is not committed to a restriction of actual desires to present desires. In other words, this seems to mean that he takes TNA as a possible construal of actualism over a lifetime. Heathwood (2011: 26) explicitly endorses TNA although he adds to it the concurrence constraint presented in the previous note. Notice however that he has nowhere explained whether adaptive preferences constitute a problem for his version of TNA and how it would deal with them.
} 
being attainable by those who have these preferences. Hence, one may object that to adopt an actualist approach to subjectivism is just to accept this worse perspective for those who have adaptive preferences without offering the means to criticize and reverse them. And this, the objection goes, is just to legitimize the oppression they have suffered. However, I will now argue that actualism understood as TNA does not have these implications. To start with, it is worth noticing that if most problematic adaptive preferences tend to lessen the level of well-being that will result from their satisfaction, this is not always the case..$^{19}$ For instance, suppose for the sake of the argument that the interdiction against smoking cannot be legitimate and that it is imposed in a certain country. Under these morally illegitimate circumstances, some of its citizens will adapt their desire; they may give up their desire to smoke and replace it with a healthier one. However, although the new desires are adapted, they could allow for higher levels of well-being. Therefore, when this is the case, Sen and Nussbaum's objection does not even get started insofar as one cannot claim that actualism diminishes the attainable well-being of those who have adapted their preferences. ${ }^{20}$

Therefore, for the objection to have some grip, we must consider problematic adaptive preferences the fulfillment of which diminishes the level of well-being that their holders may obtain in virtue of these adaptive preferences. Now, one might think that actualism faces an especially hard problem insofar as we have argued above that people's present adaptive preferences must always be taken into account as contributing to their well-being. However, and this is the crucial point introduced by TNA, it does not follow that these adaptive desires cannot change in the future for more autonomous ones. Moreover, the latter desires, if satisfied, would provide higher levels of well-being since we are precisely considering the cases in which adaptive preferences imply a diminishment of attainable well-being. Therefore, TNA does not imply that the wellbeing of people with adaptive preferences is definitely limited by their adaptive preferences. On the contrary, it underlines that in these circumstances, this diminishment may be reversed in the future, and that there is reason to reverse it grounded in an improvement of their future well-being. In other words, TNA allows one to see the negative effects of adaptive preferences on well-being and provides prudential reasons to overcome these negative effects.

To see this, consider a policy aiming at the well-being of citizens and, in particular, of those who have adaptive preferences. By definition, such a policy is concerned with the future well-being of these citizens. Now, if some preferences could lead to higher levels of well-being, then there are prudential reasons to acquire them. It follows that a policy aiming at well-being should rely on these prudential reasons. Hence, the policy is prima facie justified to help those who have adaptive preferences that diminish their attainable well-being to acquire more autonomous ones and to facilitate their fulfillment in order precisely to cancel this diminishment. In other words, even though some women under oppression have adapted their job ambitions to gender norms, a policy aiming at their well-being has prima facie reason grounded in their future good to help them, or at least allow them, to acquire and fulfill desires for the jobs that the gender norms refused to them. Thus, TNA is not limiting the well-being of

${ }^{19}$ I am grateful to an anonymous referee who pointed out such cases and their relevance to my argument.

20 This is not to say that these former smokers have not been wronged. My point is merely that beyond the fact that they have been, one cannot reproach TNA for unduly limiting their well-being. 
people who have adaptive preferences to their fulfillment, pace Sen and Nussbaum. On the contrary, TNA prima facie justifies the promotion and fulfillment of non-adaptive desires that can be acquired and that will provide higher levels of well-being.

It is nevertheless important to emphasize two points about this response to Sen and Nussbaum. The first is that we are only explaining how subjectivism should take account of adaptive preferences. As such, TNA does not claim that some actions aiming at the well-being of people having adaptive preferences are pro-tanto or even ultimately justified. Rather, TNA implies that people with adaptive preferences may have prudential reasons to change them for non-adaptive ones, from which it follows that policies or actions aiming at the good of the bearers of adaptive preferences may be prima facie justified. However, for this prima facie justification to become a pro tanto justification, it must also satisfy some autonomy or anti-paternalist constraints. Obviously, depending on one's favorite account of the latter constraints, very different policies will be pro tanto justified. One may either claim with Stoljar (2014: 251) that some policies like incentive schemes will be pro tanto justified or on the contrary that this prima facie justification is always defeated by considerations of respect or autonomy. ${ }^{21}$ In any case, TNA as such is neutral on this debate, and this is as it should be since a theory of well-being provides a basis for the justification of actions or policies aiming at people's well-being but certainly not their ultimate justification.

Second, it is important that this prima facie justification depends on the possibility of acquiring more autonomous preferences and on the gains that they would provide. As we have already seen, it may actually be impossible for some to change their preferences or to gain from this change. This in particular was our point in the case of Lucy. And even when a change is possible, it may be argued that the change is rarely or even never beneficial. For instance, Terlazzo (2017b: 245-246) argues that the change is never beneficial for adults, or at least for adults that are committed to their adaptive preferences. In any case, TNA in itself does not imply any such conclusions, since they will depend on psychological hypotheses that are independent of the TNA.

I therefore conclude that TNA provides a complete and appropriate treatment of adaptive preferences within a subjectivist approach of well-being. On the one hand, it insists that adaptive preferences are relevant to the well-being of their holder. It explains correctly that, under some circumstances, the most people with adaptive preferences could obtain is the fulfillment of these preferences. On the other hand, TNA makes full sense of the idea that while adapting their preferences has lowered their present attainable well-being, their well-being should not be unduly limited by them. This is because they may still acquire more autonomous ones in the future the fulfillment of which will provide higher levels of well-being. Hence, TNA does not legitimize oppression but offers the means to criticize its result and prima facie reasons to reverse the adaptive preferences.

\subsection{More refined versions of idealizing subjectivism?}

We are finally in a position to address a pending question: why not adopt a more refined version of subjectivism that would combine features of both actualism and counterfactualism? After all, our central argument against counterfactualism has been that it unduly excludes some adaptive preferences. A somewhat hybrid subjectivism could avoid this objection. I see two main avenues to construct a hybrid subjectivism.

${ }^{21}$ For arguments in this direction, see Jaggar 2005, Sugden 2006. 
The simplest strategy would be to claim that one's good is constituted by both actual and counterfactual desires. But this view does not fare better than the TNA. It has two defects. The first is that it would need to explain how one should compare from a prudential perspective actual and counterfactual desires. Should we give them equal worth? Or does the distance to a counterfactual desire diminish its contribution to wellbeing? And if the latter, how could we determine a decreasing ratio as a function of this distance? I do not see how we could offer justified answers to these crucial questions. In comparison, TNA avoids the problem. The accomplishment of possible desires makes one better off only to the extent that they can be possessed in the future and given the cost and probability of their acquisition and fulfillment. Notice that this response is not available to counterfactualism or mixed subjectivism, since the latter imply by definition that the fulfillment of a counterfactual desire that you may be unable to acquire nevertheless improves your well-being. If the desire cannot be acquired, you can have a measure neither of the probability of reaching it nor of the cost that this may involve. The second objection to this simple strategy is the one we have already pressed against counterfactualism: to claim that the fulfillment of a counterfactual desire one does not have and to which one is fully indifferent could make a difference in one's well-being is to offer an alienating conception of well-being.

An alternative strategy to combine features of actual and counterfactual subjectivism is Railton's conception of what is good for someone (Railton 2003: 54). According to his proposal, an object is good for an individual if and only if this individual, ideally informed and rational, would desire that the individual she actually is desire this object. The strength of this approach is that it leaves open the possibility that the ideal individual would desire that her actual self desire precisely what this actual self desires. Hence, one cannot claim that it mistakenly denies that adaptive preferences contribute to well-being. ${ }^{22}$ Nevertheless, one may wonder how the account deals with adaptive preferences. Unfortunately, no response can be drawn from Railton's proposal. ${ }^{23}$ But suppose that my ideal self would not desire that my actual self were to have my actual adaptive desires. Then, Railton's approach would fall prey to the objection we have raised against counterfactual subjectivism. So, for Railton's account to be correct, it must concur with actualism on its treatment of adaptive preference. For sure, that may still leave room for a debate between TNA and Railton's view but it will have to rely on grounds that are external to the problem of adaptive preferences. Therefore, the point of the present paper is preserved: insofar as adaptive preferences are concerned, subjectivism should be actualist.

\section{Conclusion}

In this paper, I have attempted to contribute to the emerging interest in actualist versions of subjectivism. Given the numerous types of defective desires or pro-attitudes that subjectivism must consider, and the multiple versions of actualism and counterfactualism that one may formulate, the debate that opposes them is far from being closed. In particular, I haven't said anything in favor of or against the introduction of an idealizing condition of information. Nevertheless, I have shown that, at least with

\footnotetext{
22 Thanks to David Sobel for raising this difficulty.

${ }^{23}$ Indeed, Railton assumes this feature of his account since his aim is precisely not to provide a determinate normative theory of what is good for one but rather to present a general strategy that is available to offer a version of metaethical naturalism.
} 
regard to the significant problem of adaptive preferences, the introduction of an idealizing condition that erases or replaces these preferences is not the path that subjectivism should follow. To acquire problematic adaptive preferences is surely bad in general since it diminishes the level of well-being that may be attained. To this extent, it is a bit like being harmed. But to correct a harm, we must not erase the fact that it happened at the risk of inflicting more harm. Similarly, considering the well-being of a person that has adaptive preferences requires us to acknowledge this actual and present state of the person, but also what she could now benefit from, and how her situation can improve if it can. And this is precisely what actualism as TNA contends. ${ }^{24}$

\section{References}

Baber, Harriet E. 2007. Adaptive preference. Social Theory and Practice, 33(1): 105-126. Brandt, Richard B. 1998. A Theory of the Good and the Right, 2nd edn (Oxford: Clarendon Press)

Bratman, Michael. 1987. Intention, plans, and practical reason (Cambridge, MA: Harvard University Press)

Bruckner, Donald W. In defense of adaptive preferences, Philosophical Studies, 142(3): 307-324

Colburn, Ben. 2011. Autonomy and adaptive preferences, Utilitas, 23(1): 52-71

Christman, John. 1991. Autonomy and personal history, Canadian Journal of Philosophy, 21(1): $1-24$

Dorsey, Dale. 2012. Subjectivism without desire, Philosophical Review, 121(3): 407-442

- - 2013a. Desire-satisfaction and Welfare as Temporal, Ethical Theory and Moral Practice, 16(1): 151-171.

- - 2013b. Adaptation, Autonomy, and Authority, in Räikkä J. and J. Varelius (eds.) Adaptation and Autonomy: Adaptive Preferences in Enhancing and Ending Life (Berlin, Heidelberg: Springer), p. 27-47

- - 2017. Idealization and the Heart of Subjectivism, Noûs, 51(1): 196-217

Dworkin, Gerald. 1988. The theory and practice of autonomy (Cambridge: Cambridge University Press)

Elster, Jon. 1983. Sour grapes (Cambridge: Cambridge University Press and Paris: Editions de la maison des sciences de l'homme)

Enoch, David. 2020. False Consciousness for Liberals, Part I: Consent, Autonomy, and Adaptive Preferences, Philosophical Review, 129(2): 159-210

Fletcher, Guy. 2013. A fresh start for the objective-list theory of well-being, Utilitas, 25(2): 206-220.

Frankfurt, Harry. 2018. Freedom of the Will and the Concept of a Person, in Agency and Responsibility (Routledge), p. 77-91

\footnotetext{
${ }^{24}$ I thank Donald Bruckner for his useful comments at the Kansas Workshop on Well-being 5. I am also grateful to two anonymous referees of this journal and to audiences at UKLeuven, the Metaethics seminar in Paris, the Conative Nudges conference in Rennes, the $4^{\text {th }}$ international conference Economics and Philosophy in Lyon and the KWoW 5 in Lawrence. This paper forms part of the research project "ValFree" (The Value of Choice, grant No. ANR-16-CE41-0002-01) of the French National Agency for Research whose financial support is gratefully acknowledged.
} 
Heathwood, Chris. 2005. The problem of defective desires, Australasian Journal of Philosophy, 83(4): 487-504

- - 2006. Desire satisfactionism and hedonism, Philosophical Studies, 128(3): 539-563

- - 2011. Preferentism and self-sacrifice, Pacific Philosophical Quarterly, 92(1): 18-38

Jaggar, Alison M. 2005. "Saving Amina": Global justice for women and intercultural dialogue, Ethics \& International Affairs, 19(3), 55-75

Khader, Serena J. 2013. Gendered Adaptive Preferences, Autonomy, and End of Life Decisions, in Räikkä J. and J. Varelius (eds.) Adaptation and Autonomy: Adaptive Preferences in Enhancing and Ending Life (Berlin, Heidelberg: Springer), p. 81-100

Lemaire, Stéphane. 2016. A Stringent but Critical Actualist Subjectivism about WellBeing, Les Ateliers de l'éthique / The Ethics Forum, 11(2): 133-150. https://doi.org/10.7202/1041770ar

Lin, Eden. 2019. Why Subjectivists About Welfare Needn't Idealize, Pacific Philosophical Quarterly, 100(1): 2-23

Murphy, Mark C. 1999. The Simple Desire-Fulfillment Theory, Noûs 33(2): 247-272

Narayan, Uma. 2002. Minds of their own: Choices, autonomy, cultural practices, and other women, in Anthony L. M. and C. Witt (eds.) A mind of one's own: Feminist essays on reason and objectivity, $2^{\circ}$ edn (Boulder, CO: Westview), p. 418-432

Nussbaum, Martha C. 2001. Women and human development: The capabilities approach (Cambridge University Press)

Parfit, Derek. 2011. On what matters. vol. 1 (Oxford: Oxford University Press)

Rabinowicz, W. and J. Österberg. 1996. Value based on preferences: On two interpretations of preference utilitarianism. Economics \& Philosophy, 12(1), 1-27

Railton, Peter. 2003. Facts and Values, in Facts, values, and norms: Essays toward a morality of consequence (Cambridge University Press), p. 43-68

Raz, Joseph. 1986. The Morality of Freedom (Oxford: Clarendon Press)

Sen, Amartya. 1984. Rights and capabilities. In Resources, values, and development (Cambridge, MA: Harvard University Press)

Sidgwick, Henry. 1907. The Methods of Ethics, 7th edn. (Cambridge, MA: Harvard University Press)

Sobel, David. 2009. Subjectivism and idealization, Ethics, 119(2), 336-352

Stoljar, Natalie. 2014. Autonomy and adaptive preference formation, in Veltman A. and M. Piper (eds.) Autonomy, Oppression, and Gender (Oxford University Press), p. 227-52

Sugden, Robert. 2006. What we desire, what we have reason to desire, whatever we might desire: Mill and Sen on the value of opportunity, Utilitas, 18(1), 33-51

Superson, Anita. 2005. Deformed desires and informed desire tests, Hypatia, 20(4), 109126

Terlazzo, Rosa. 2017a. Must Adaptive Preferences Be Prudentially Bad for Us?, Journal of the American Philosophical Association, 3(4), 412-429

- $-2017 \mathrm{~b}$. When is Non-Ideal Theory Too Ideal? Adaptive Preferences, Children, and Ideal Theory, in Vallier K. and M. Weber (eds.) Political Utopias: Contemporary Debates (New York: Oxford University Press), p. 233-252

Tiberius, Valery. 2018. Well-being as Value Fulfillment: How We Can Help Each Other to Live Well (New-York: Oxford University Press) 
